\title{
Overt hyperthyroidism and venous thrombosis: what is the association?
}

\author{
Chakir Mariame* \\ University Hospital \\ Mohammed the VIth, \\ Department of Cardiology, \\ Marrakesh, Morocco
}

KEYWORDS: hyperthyroidism, venous thrombosis, pulmonary embolism. CITATION: Cardiol Croat. 2019;14(9-10):244. | https://doi.org/10.15836/ccar2019.244

*ADDRESS FOR CORRESPONDENCE: Chakir Mariame, 139 Lot Izdihar Route de Safi, Marrakesh, Morocco. / Phone: 00212642083494 / E-mail: mariamechakir@hotmail.com

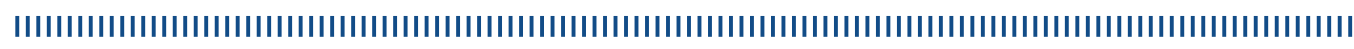

Introduction: Patients that present overt hyperthyroidism, are more prone to a venous or arterial thrombosis ${ }^{1-3}$. Multiple mechanisms can explain the procoagulant changes in the hemostatic system in this population. Hereby, we report the case of a patient with Grave's disease, presenting overt hyperthyroidism, associated with pulmonary embolism. The aim of this report is to emphasize the pathophysiological patterns responsible of the emergence of venous thrombosis (VT) in hyperthyroidism, as well as to discuss the increased probability of VT in this population.

Case report: 44-year-old woman, with a past medical history of Grave's disease, treated during the previous year before her admission by carbimazole $30 \mathrm{mg}$ daily, presented to the emergency department with a fever, productive cough, hemoptysis and painful breathing during the last couple of days. In the previous weeks she had noticed swelling and redness of her right leg. The diagnosis of VT of the lower limb was confirmed by a venous ultrasound of the lower extremities and she was put on vitamin $\mathrm{K}$ antagonists 10 days before she presented to the emergency department for her exertional dyspnea. No risk factors for venous thrombosis were present. On physical examination she had a breathing frequency of 30 per minute, an air saturation of $92 \%$, a temperature of $38.6{ }^{\circ} \mathrm{C}$ and, pulse rate of 120 beats per minute. The ECG showed a sinus tachycardia of $120 \mathrm{bpm}$ and an S1Q3 aspect. CT scan has shown proximal right pulmonary emboli in the right upper and lower lobe with infarction of the basal right lung. Laboratory data revealed a TSH of $0.005 \mathrm{mE} / \mathrm{l}$ and FT4 of $>70 \mathrm{pmol} / \mathrm{l}$. The thrombophilic tests were negative. The patient received heparin, followed by oral anticoagulant therapy with a vitamin $\mathrm{K}$ antagonist with a favorable evolution. By presenting this case, our aim is to emphasize the fact that hyperthyroidism can be a risk factor for venous thromboembolism, as indicated previously by a small number of retrospective studies. This patient had no identifiable risk factors for VTE. Possible predisposing factors for the development of VT and PE in patients with thyrotoxicosis are also in line with Virchow's triad.

Conclusion: Patients with hyperthyroidism may often have accompanying endothelial dysfunction, decreased fibrinolytic activity, and hypercoagulable states which contribute to the development of VT.
RECEIVED:

July 21, 2019

ACCEPTED:

September 16, 2019

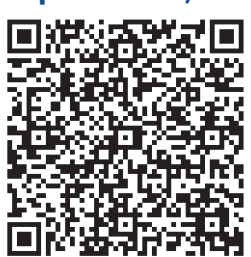

$\square$ Cardiologia Croatica 2019;14(9-10):244.

LITERATURE IIIIIIIIIIIIIIIIIIIIIIIIIIIIIIIIIIIIIIIIIIIIIIIIIIIIIIIIIIIIIIIIIIIIIIIIIIIIIIIIIIIIIIIIIIIIIIIIIIIIIII

1. Franchini M, Lippi G, Targher G. Hyperthyroidism and venous thrombosis: a casual or causal association? A systematic literature review. Clin Appl Thromb Hemost. 2011 Aug;17(4):387-92. https://doi.org/10.1177/1076029610364521

2. Franchini M, Montagnana M, Manzato F, Vescovi PP. Thyroid dysfunction and hemostasis: an issue still unresolved. Semin Thromb Hemost. 2009 Apr;35(3):288-94. https://doi.org/10.1055/s-0029-1222607

3. Marongiu F, Cauli C, Mariotti S. Thyroid, hemostasis and thrombosis. J Endocrinol Invest. 2004 Dec;27(11):1065-71. https://doi.org/10.1007/BF03345311 